\title{
Exposure measurement, risk assessment and source identification for exposure of traffic assistants to particle-bound PAHs in Tianjin, China
}

\author{
Xiaodan Xue ${ }^{1}$, Yan You ${ }^{2,3}$, Jianhui $\mathrm{Wu}^{2}$, Bin $\mathrm{Han}^{2,4}$, Zhipeng Bai ${ }^{2,4}$, Naijun Tang ${ }^{1}$, Liwen Zhang ${ }^{1, *}$ \\ 1. College of Public Health, Tianjin Medical University, Tianjin 300070, China. E-mail: xuexiaodan@tijmu.edu.cn \\ 2. College of Environmental Science and Engineering, Nankai University, TianJin 300071, China \\ 3. Research Center for Eco-Environmental Sciences, Chinese Academy of Sciences, Beijing 100085, China \\ 4. Chinese Research Academy of Environmental Sciences, Beijing 100012, China
}

\section{A R T I C L E I N F O}

\section{Article history:}

Received 07 March 2013

revised 11 April 2013

accepted 03 July 2013

\section{Keywords:}

polycyclic aromatic hydrocarbons

exposure

risk assessment

traffic assistants

source identification

DOI: 10.1016/S1001-0742(13)60427-1

\begin{abstract}
A B S T R A C T
To investigate the levels of exposure to particulate-bound polycyclic aromatic hydrocarbon (PAH) and to estimate the risk these levels pose to traffic assistants (TAs) in Tianjin (a megacity in North China), a measurement campaign (33 all-day exposure samples, 25 occupational-exposure samples and 10 indoor samples) was conducted to characterize the TAs' exposure to PAHs, assess the cancer risk and identify the potential sources of exposure. The average total exposure concentration of 14 PAHs was approximately $2871 \pm 928 \mathrm{ng} / \mathrm{m}^{3}$ (on-duty), and $1622 \pm 457 \mathrm{ng} / \mathrm{m}^{3}$ (all-day). The indoor PAHs level was $1257 \pm 107 \mathrm{ng} / \mathrm{m}^{3}$. After 8000 Monte Carlo simulations, the cancer risk resulting from exposure to PAHs was found to be approximately $1.05 \times 10^{-4}$. A multivariate analysis was applied to identify the potential sources, and the results showed that, in addition to vehicle exhaust, coal combustion and cooking fumes were also another two important contributors to personal PAH exposure. The diagnostic ratios of PAH compounds agree with the source apportionment results derived from principal component analysis.
\end{abstract}

\section{Introduction}

Polycyclic aromatic hydrocarbons (PAHs) are unique substances detected in various environments, that are also considered toxic, carcinogenic and mutagenic (Arfsten et al., 1996; Fent and Batscher, 2000). Most of the PAHs in the atmosphere arise from the emissions resulting from combustion, including natural emissions such as the forest fires (Gabos et al., 2001) and volcanoes (Zolotov and Shock, 2000), and anthropogenic emissions from fossil fuel (coal, petroleum and so on) combustion (Wild and Jones, 1995), tobacco smoke (Vanrooij et al., 1994), cooking operations (Mumford et al., 1995) and other domestic combustion processes (Oanh et al., 1999).

With the increasing numbers of vehicles, motor vehi-

*Corresponding author. E-mail: zhangliwen@tijmu.edu.cn cle exhaust has become a significant emission source of PAHs. Numerous studies have reported a high level of PAH exposure for traffic policemen. A total of 28 traffic policemen and 10 road builders were studied for PAH exposure in downtown Budapest, Hungary, during their working hours (Szaniszló and Ungváry, 2001). The results indicated that the PAH exposure level for traffic policemen was $60.7 \mathrm{ng} / \mathrm{m}^{3}$, comparable to the exposure levels in most other European cities. Another personal exposure investigation performed among 44 traffic policemen and 45 office policemen in Bangkok, Thailand found that PAH exposure among traffic policemen $\left(72.79 \mathrm{ng} / \mathrm{m}^{3}\right)$ was much higher than exposure levels for office staff $\left(6.88 \mathrm{ng} / \mathrm{m}^{3}\right)$ (Ruchirawa et al., 2002). In China, Liu et al. (2007b, $2007 \mathrm{c}$ ) reported the PAH exposure levels for policeman in Beijing, and the results showed that exposure levels to 16 gaseous and particulate PAHs for the traffic police were found to be $(1525 \pm 759)$ and $(148 \pm 118) \mathrm{ng} / \mathrm{m}^{3}$, 
respectively, representing 2-2.5 times higher levels than at the control sites. The daily inhalation exposure of policeman was about $277 \mathrm{ng} /(\mathrm{kg} \cdot$ day $)$. In Tianjin City near Beijing, the traffic police have an exposure level (total for 16 PAHs of approximately $867.5 \mathrm{ng} / \mathrm{m}^{3}$ ) (Hu et al., 2007) close to the exposure level for Beijing police.

From November of 2004, in response to the worsening traffic situation resulting from the huge increment in automobiles, the first batch of traffic assistants (who assist the traffic police to manage traffic personnel, primarily responsible for the order of pedestrians and vehicles in heavy traffic road sections or junctions) (approximately 1100) was recruited to assist the traffic policemen in Tianjin. At present, the number of traffic assistants (TAs) in this city is approximately 3000. Although PAHs from automobile exhaust in their occupational environment may be the most important part of the exposure of TAs to PAHs, PAH exposure from cooking, tobacco smoke and other sources can play moderate roles. The TAs constitute individuals who will receive exceptional multi-way exposure.

From the short review above, some questions have been raised concerning the exposure of the TAs to PAHs. What is the PAH exposure level and what is the exposure profile of TAs in Tianjin? What type of risk does the inhalation of PAHs pose? Is the occupational environmental exposure the only or the major source for total inhalation exposure?

In this study, using survey questionnaires, personal sampling and chemical analysis, the PAH exposure level and profile were investigated and exposure risk was then assessed by Monte Carlo simulation (Hu et al., 2007; Liu et al., 2007b). Based on the characterization of the exposure profile and the personal exposure database, the data was rearranged by the principal component analysis method (Larsen and Baker, 2003; Manoli et al., 2004) and the contribution of major sources to the inhalation exposure could be derived. The risk assessment results can provide information on the risk for this special population. All of the above results can improve the reliability of the exposure-response relationship and provide the sources of the major contributors, which is important to control the exposure and promote the health of TAs for the purpose of environmental and occupational health management.

\section{Methods}

\subsection{Sampling strategy}

All samples were collected in Tianjin City from July to August in 2007. Tianjin is a typical metropolis of China, with a population of approximately 11.7 million. Tianjin is located in the north of China, at the lower reaches of the Haihe River and adjacent to the Bohai Sea. Tianjin has distinct seasons with an annual mean temperature of $13.1^{\circ} \mathrm{C}$, and the average rainfall is $500-700 \mathrm{~mm}$. Tianjin is an important industrial center and a well-developed hub with a sea-land-air transportation network. At the end of 2008, there were approximately 909,600 vehicles in Tianjin (National Statistics Bureau, 2008).

Sixteen representative sites (T-shaped crossing centers and intersection centers, Fig. 1) in Tianjin were selected for sampling and 58 TAs were recruited as subjects in this study. Everyone was trained to record the time activity table and operate the sampling instruments. All of the samples can be organized into 3 classes: Class 1 (onduty exposure samples), 25 samples collected by fixing the personal environmental monitor (PEM) in the center of the working road during the working time of the TAs (from 8:00 a.m. to 2:00 p.m.); Class 2 (all-day exposure samples), 33 samples collected by carrying the PEM with the subject for $24 \mathrm{hr}$; and Class 3 (indoor samples), 10 samples collected by fixing the PEM in the subject's home for $24 \mathrm{hr}$ (from 8:00 a.m. to next day at 8:00 a.m.).

$\mathrm{PM}_{10}$ samples were collected on quartz filters $(37 \mathrm{~mm}$, Pall Filter Co., USA) by Model 200 personal environmental monitors $\left(\mathrm{PEM}^{\mathrm{TM}}\right.$, SKC Co., USA) and the size-cut head was connected to the PEM by a plastic tube $(75 \mathrm{~cm})$. The sample head was fixed on the collar to collect personal samples in the breathing zone, and the samplers were operated at a constant flow rate of $10 \mathrm{~L} / \mathrm{min}$. Both the indoor and all-day samples were collected by fixing the sample head at $1.5 \mathrm{~m}$ above ground level. The sampler was set in the center of the room or road center. Before sampling, all quartz filters were pretreated by baking in an oven at $450^{\circ} \mathrm{C}$ for $4.5 \mathrm{hr}$ to volatilize any organic contaminants. Samplers were calibrated by a Buck calibrator (M30, Buck Co., USA). During the whole sampling, the temperature ranged from 19.2 to $35.1^{\circ} \mathrm{C}$ and the atmospheric pressure ranged from 99,400 to $101,700 \mathrm{~Pa}$. The lowest relative humidity was $27 \%$. After sampling, the filters were packed with aluminum foil to avoid light and were conditioned at a constant temperature of $20^{\circ} \mathrm{C}$ with a constant relative humidity of $45 \%$ for $12 \mathrm{hr}$ before weighing. The filters were stored in a refrigerator (below $-15^{\circ} \mathrm{C}$ ) until extraction. All filters were extracted within 2 weeks after sampling.

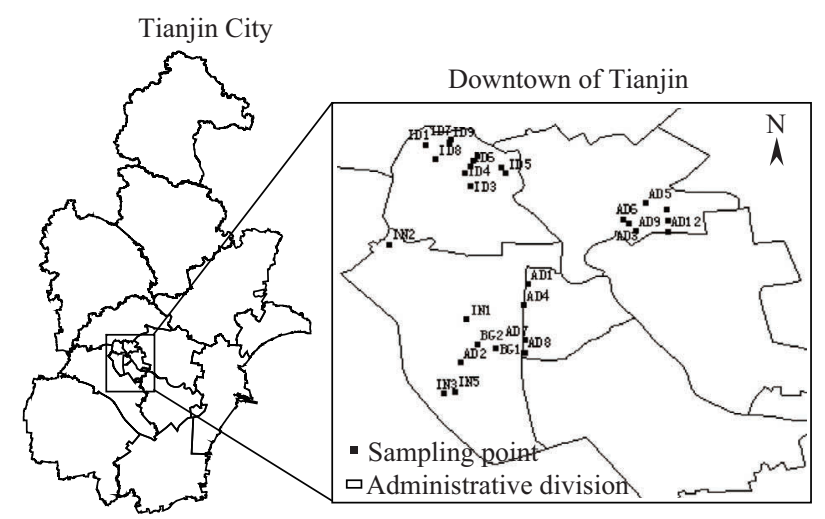

Fig. 1 Map of the sample site. IN1 to IN5: indoor samples, AD1 to AD12: all-day samples, ID1 to ID12: on-duty samples. 


\subsection{Chemical analysis}

The PAHs on filters were extracted with $15 \mathrm{~mL}$ dichloromethane $\left(\mathrm{MeCl}_{2}\right)$ in an ultrasonic extractor (AS3120, AutoScience Co., Tianjin, China) for $15 \mathrm{~min}$ and then the insoluble part was separated by centrifugation (0406-1, Shanghai Medical Instrument Co., Shanghai, China) at $3000 \mathrm{r} / \mathrm{min}$ for $10 \mathrm{~min}$. The procedure was repeated 3 times. The solvent volume was reduced using a rotary evaporator (RE52CS, YaRong Biochemistry Instrument Co., Shanghai, China) under $-20,000 \mathrm{~Pa}$ and $40^{\circ} \mathrm{C}$ after extraction. A silica gel column previously activated at $450^{\circ} \mathrm{C}$ for $4 \mathrm{hr}$ was used for separating the compound groups. The aliphatic compounds were eluted with 40 $\mathrm{mL}$ of hexane, the PAH fraction was collected with 120 $\mathrm{mL}$ of $1: 1(V / V)$ dichloromethane/hexane mixture, and the remaining polar components were eluted with $50 \mathrm{~mL}$ of dichloromethane. The PAH fraction was then evaporated (-80,000 $\mathrm{Pa}$ and $45^{\circ} \mathrm{C}$ ) and reduced under $\mathrm{N}_{2}$ to approximately $0.5 \mathrm{~mL}$. All sample extracts were transferred to individual amber $2 \mathrm{~mL}$ glass HPLC vials and stored in the refrigerator $\left(-4^{\circ} \mathrm{C}\right)$ until subsequent analysis.

The external standard solutions were prepared including 18 PAHs: naphthalene (Nap), acenaphthylene (Aci), acenaphthene (Ace), fluorene (Flu), phenanthrene (Phe), anthracene (Ant), fluoranthene (Fluo), pyrene (Pyr), benz(a)anthracene (BaA), chrysene (Chr), benzo(b)fluoranthene (BbFlu), benzo(k)fluoranthene (BkFlu), benzo(e)pyrene (BeP), benzo(a)pyrene (BaP), indeno(1,2,3-cd)pyrene (InP), dibenz(a,h)anthracene (DiBahA), benzo(g,h,i)perylene (BghiP) and coronene (Cor). The mixture of EPA610 (48743, 16 PAHs of EPA listed), BeP (36962) and Cor (36963) were purchased from Supelco Co. in USA. These standard PAHs were diluted with dichloromethane to 4 different concentration levels in the range of $0.08-40 \mu \mathrm{g} / \mathrm{mL}$.

The 18 PAHs were identified and quantitated using a GC-MSD system (GC6890-MSD5975, Agilent, USA). The GC used a DB5-MS (J\&W Scientific Technologies, USA) fused silica capillary column $(30 \mathrm{~m} \times 0.25 \mathrm{~mm}$ i.d. $\times 0.25 \mu \mathrm{m}$ phase thickness), and helium was employed as carrier gas at $1.2 \mathrm{~mL} / \mathrm{min}$. Then $1 \mu \mathrm{L}$ of each extract was injected into the GC in splitless mode using an auto injector (7683B, Agilent, USA). The GC injector port was maintained at $290^{\circ} \mathrm{C}$. The GC oven was programmed with an initial temperature of $70^{\circ} \mathrm{C}$, held for $2 \mathrm{~min}$, heated at a rate of $8^{\circ} \mathrm{C} / \mathrm{min}$ to $295^{\circ} \mathrm{C}$, and held for $15 \mathrm{~min}$. The transfer line between the GC and MSD was held at $280^{\circ} \mathrm{C}$. The MSD was operated under the following conditions: Electron ionization mode with energy of (nominal) $70 \mathrm{eV}$, heptacosa as tuning standard, the Qua-Detector temperature at $230^{\circ} \mathrm{C}$, and mass range of 50-600 amu. Retention time comparisons to authentic standards and reference mass spectra (National Institute of Standards and Technology) were used to perform qualitative analysis. The chromatogram peak areas were used to perform quan- titative analysis in selected ion mode (SIM), the quantified ions included the following: $128 \mathrm{amu}$ (Nap), $152 \mathrm{amu}$ (Aci), 153 amu (Ace), 166 amu (Flu), 178 amu (Phe, Ant), 202 amu (Fluo, Pyr), 228 amu (BaA, Chr), 252 amu (BbFlu, BkFlu, BeP, BaP), 276 amu (InP, BghiP), $278 \mathrm{amu}$ (DiBahA), and $300 \mathrm{amu}$ (Cor). The data from the GC/MS analysis were processed using a ChemStation data analysis system.

\subsection{Statistical analysis of data}

\subsubsection{Calculating BaP equivalent concentrations}

$\mathrm{BaP}$ is the most intensively studied PAH species in animal tests and is the only PAH that has been tested for carcinogenicity in inhalation (WHO, 2000). The toxic equivalency factors (TEFs) were defined to rank the relative carcinogenic potential of other PAHs compared to BaP. The TEF for BaP was 1 (Nisbet and LaGoy, 1992). The TEFs can quantitatively represent the health hazards of PAHs. The relative toxicities of other PAHs can be computed and normalized by an index list based on the toxicity of $\mathrm{BaP}$, as described in Eq.(1).

$\mathrm{TEC}_{\mathrm{Bap}}=\mathrm{Con}_{\mathrm{PAHs}} \times \mathrm{TEF}_{\mathrm{BaP}}$

where, $\operatorname{TEC}_{\mathrm{BaP}}\left(\mathrm{ng} / \mathrm{m}^{3}\right)$ is the normalized equivalent concentration for toxicity of $\mathrm{BaP}$ over 24 hours (Zhang et

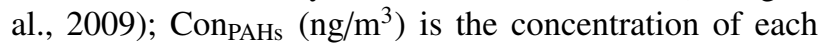
PAH compound over the period of 24 hours; $\mathrm{TEF}_{\mathrm{BaP}}$ is the toxicity equivalent factor based on $\mathrm{BaP}$. After the calculation of $\mathrm{TEC}_{\mathrm{BaP}}$, the total toxicity concentration was obtained by adding all of the $\mathrm{TEC}_{\mathrm{BaP}}$ together.

\subsubsection{Monte Carlo simulation of the risk based on an incremental lifetime cancer risk model}

An incremental lifetime cancer risk (ILCR) model was applied in this study to assess the lifetime risk of the exposure of the TAs to PAHs. The ILCR model can be used in estimating the incremental probability of an individual developing a tumor over a lifetime and described as Eq. (2):

$\mathrm{ILCR}=\frac{\mathrm{CSF} \times \mathrm{TTEC}_{\mathrm{BaP}} \times \mathrm{IR} \times \mathrm{EF} \times \mathrm{ED}}{\mathrm{BW} \times \mathrm{AT}}$

where, ILCR is the incremental lifetime cancer risk from the occupational exposure to PAHs; CSF $((\mathrm{kg} \cdot \mathrm{day}) / \mathrm{mg})$ is the inhalation cancer slope factor of $\mathrm{BaP}$; TTEC $_{\mathrm{BaP}}$ $\left(\mathrm{ng} / \mathrm{m}^{3}\right)$ is the total equivalent concentration of $14 \mathrm{PAHs}$ compared to the toxicity of BaP over 24 hours; IR $\left(\mathrm{m}^{3} / \mathrm{hr}\right)$ is the inhalation rate; $\mathrm{EF}$ ( 250 days/yr) is the exposure frequency, adapted from the Human Health Evaluation Manual (1991) (USEPA, 1991); ED (25 years) is the exposure duration, adapted from Human Health Evaluation Manual (1991) (USEPA, 1991); BW is body weight (lognormal $(59.78,1.07))$, adapted from Department of Health, 
ROC (Chen and Liao, 2006); AT is the average life time (70 years for carcinogens).

The Crystal Ball 7.2 was used as a tool in the Monte Carlo random simulation in risk assessment.

\subsubsection{Source identification}

Principal component analysis (PCA) was performed using PASW Statistics 18.0 software.

\subsection{QA and QC}

No significant contamination of solvents, apparatus and background level was found. A filter spiked with $2 \mathrm{~mL}$ of the standard solution was extracted as a substitute for an actual sample to check the recovery. The PAH concentrations were corrected for the recovery efficiency of extraction. The mean field recovery was Nap (58.99\%), Aci (39.92\%), Ace (50.73\%), Flu (58.70\%), Phe (97.42\%), Ant (71.93\%), Fluo (82.39\%), Pyr (76.15\%), BaA (76.26\%), Chr (74.76\%), BbFlu (89.16\%), BkFlu (72.18\%), BeP (72.45\%), BaP (75.47\%), InP (111.21\%), DiBahA (76.82\%), BghiP (73.72\%) and Cor (78.11\%), and the limitation of machine detection (LMD) ranged from $0.01 \mu \mathrm{g} / \mathrm{mL}$ (Aci) to $0.15 \mu \mathrm{g} / \mathrm{mL}$ (Nap).

All of the questionnaires were collected by a professional staff and input using Epidata 3.0 software.

\section{Results and discussion}

\subsection{Exposure level of PAHs}

Nap, Aci, Ace and Flu had a poor recovery (less than 60\%) or were not detected in most of the samples, so only 14 PAHs (Phe, Ant, Fluo, Pyr, BaA, Chr, BbFlu, BkFlu, BeP, $\mathrm{BaP}$, InP, DiBahA, BghiP and Cor) were discussed in this study.

The PAH exposure levels for the TAs are shown in Fig. 2. The total exposure concentrations of $14 \mathrm{PAHs}$ are approximately $2871 \mathrm{ng} / \mathrm{m}^{3}$ (on duty) and $1622 \mathrm{ng} / \mathrm{m}^{3}$ (all-day). The total indoor PAH level is $1257 \mathrm{ng} / \mathrm{m}^{3}$. Among the 14 PAHs, Fluo $\left(41.67 \mathrm{ng} / \mathrm{m}^{3}\right)$ is the least abundant compound, and Cor $\left(449.72 \mathrm{ng} / \mathrm{m}^{3}\right)$ is the most abundant compound in the on-duty samples. Fluo $(30.60$ $\left.\mathrm{ng} / \mathrm{m}^{3}\right)$ is the least abundant compound, and InP (233.78 $\mathrm{ng} / \mathrm{m}^{3}$ ) is the most abundant compound in all-day samples, Fluo $\left(11.76 \mathrm{ng} / \mathrm{m}^{3}\right)$ is the least abundant compound, and InP $\left(211.66 \mathrm{ng} / \mathrm{m}^{3}\right)$ is the most abundant compound in indoor samples. Except for $\mathrm{BaP}$, the concentrations of other compounds in exposure samples show the following sequence: on-duty $>$ all-day $>$ indoor. Traffic emission makes a huge contribution to air quality on the job site. Due to the diversity of traffic flow in different places, the PAH exposure level for TAs on duty varied from 90.91 to $886.36 \mathrm{ng} / \mathrm{m}^{3}$. There is no significant difference between the daily average exposure level and the indoor level. Most of the Cor comes from automobile exhaust emissions, so exposure on-duty shows the highest level $\left(449.72 \mathrm{ng} / \mathrm{m}^{3}\right)$, more than the all-day exposure $\left(222.00 \mathrm{ng} / \mathrm{m}^{3}\right)$. The indoor Cor $\left(197.58 \mathrm{ng} / \mathrm{m}^{3}\right)$ shows the lowest concentration.

The concentration of $\mathrm{BaP}$ inhaled by TAs in Tianjin was $310.61 \mathrm{ng} / \mathrm{m}^{3}$ (on-duty), $142.52 \mathrm{ng} / \mathrm{m}^{3}$ (all-day) and $117.83 \mathrm{ng} / \mathrm{m}^{3}$ (indoor). The daily average concentration limit promulgated by the State Environmental Protection
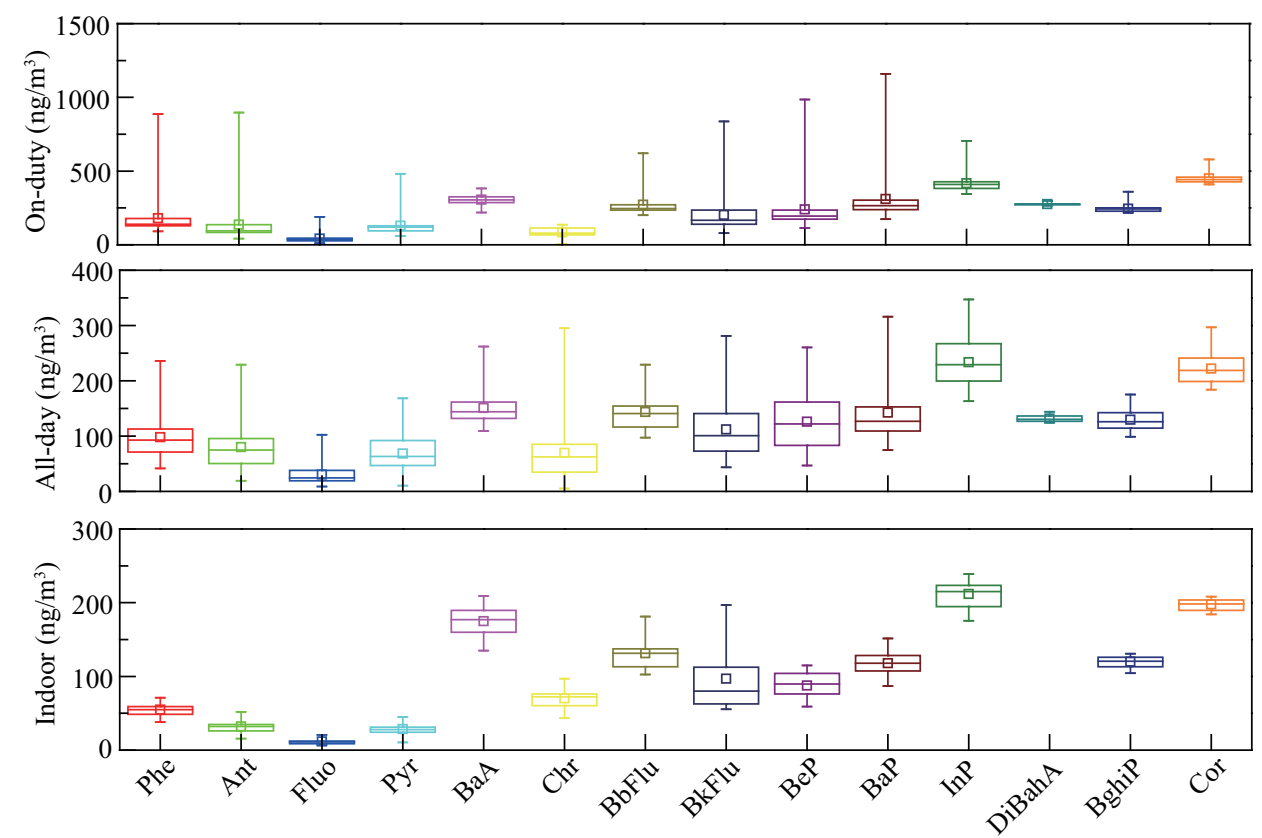

Fig. 2 PAHs exposure level of TAs in Tianjin. 
Department of China (GB3095-1996) is less than $10 \mathrm{ng} / \mathrm{m}^{3}$ and the criterion of WHO is $1 \mathrm{ng} / \mathrm{m}^{3}$ (WHO, 1987). The exposure levels for TAs are far higher than those 2 standards and in a dangerous situation, and an intervention to control exposure and reduce risk is necessary.

Comparing the results of this study, the PAHs exposure level for the TAs in Tianjin was lower than the PAH exposure of highway toll station workers in Taiwan and PAH exposure levels of traffic police in Tianjin according to the research of Hu et al. (2007). The PAH exposure level for the TAs in Tianjin is higher than the PAH exposure level of traffic policemen in Budapest (Szaniszló and Ungváry, 2001) and in Beijing (Liu et al., 2007a, 2007b; Zhang et al., 2006). The highway toll station staff has a long exposure time and more direct exposure, and the Beijing traffic police during the summer study period encounter volatile gaseous compounds caused mainly by the traffic.

\subsection{Characterization of the personal exposure to PAHs}

Comparing the daily exposure profile and exposure profile on duty, most of the PAHs show the same level between on duty and all day, but compounds with 3-4 rings show a low abundance, which can be explained by the occupational contribution playing an important role in the total $\mathrm{PAH}$ exposure of the TAs.

Comparing the smoking status, there were obvious differences between males and females (Table 1). Males showed a higher PAH exposure level than females from the smoking status because most of the smokers were male. Environmental tobacco smoke (ETS) and cooking fumes $(\mathrm{CF})$ are 2 more sources of PAH exposure. The source profiles of these 2 sources have been published in another paper by this author (Zhang et al., 2009). Smoking status and more time spent in cooking would raise the PAH exposure concentration up to a higher level. Some source characteristics can be determined from the relative exposure concentration of every PAH species. The exposure concentration and profile for females is similar to nonsmoker exposure concentration and profile of the males is similar to the exposure concentration and profile of a smoker. The exposure concentration increases with the times spent in cooking. After comparing the differences between the PAH exposure levels according to smoking status and gender, we find that most of the smokers are male, and the cooking fumes make an important contribution to the exposure increase from male to female. The concentrations of BaA, Chr, BbFlu, DiBahA and Cor show less change.

The diagnostic ratio of PAH isomeric compounds can be used for qualitative investigation of the source contribution. Five specific ratios were applied in this study to identify the source of PAHs: InP/(InP+BghiP), BaP/BghiP, $\mathrm{Flu} /(\mathrm{Flu}+\mathrm{Pyr}), \mathrm{Ant} /(\mathrm{Ant}+\mathrm{Phe})$ and $\mathrm{BaA} /(\mathrm{BaA}+\mathrm{Chr})$. The diagnostic ratios in some other publications as well as in this study are shown in Table 2.
In this study, most of the $\mathrm{InP} /(\mathrm{InP}+\mathrm{BghiP})$ ratios were approximately $0.63-0.64$. This ratio in smokers was higher than the ratio in nonsmokers. The sample sites in this study were in urban Tianjin that had a number of gasoline engines on the roads, so the ratio in the on duty samples was lower than the ratio in the all day and indoor samples because of the contribution of gasoline engines. Emission from gasoline engines has a low ratio.

Most of the ratios of $\mathrm{BaP} / \mathrm{BghiP}$ varied from 0.95 to 1.27. This ratio in smokers was higher than in nonsmokers, and males showed a higher ratio than females because of the ETS (BaP/BghiP in ETS is approximately 1.89) driving the ratio up. This ratio increased with the daily cooking frequency, because of the high value of CF. The ratio for on-duty had a larger value than the ratio for all day and indoor samples. Others sources can be found, but gasoline and diesel engine emissions were the major contributors to the exposure of TAs to PAHs just like ETS, etc.

For the ratio of Flu/(Flu+Pyr), all day samples and indoor samples were 0.30 higher than on-duty samples (0.24), and females and nonsmokers were 0.29 lower than males and smokers (0.31). This ratio increased with an increase in cooking frequency. Comparing the ratios for different sources with the literature, gasoline engines were found to be less than 0.5 , and CF and ETS were found to be more than 0.5 . The contribution of the gasoline engine decreased the ratio, but the contributions of CF and ETS increased the ratio. The frequency of cooking drives the ratio up to a higher level. Most of the smokers were male. Therefore, the ETS source produced the same contribution for males and smokers (an increase in this ratio).

For the ratio Ant/(Ant+Phe), the sequence of indoor $<$ on-duty $<$ all-day was shown (Table 2). Smokers (0.46) showed a higher ratio than nonsmokers (0.44), and females (0.43) showed a lower ratio than males (0.46). Cooking frequency had a positive effect on the increase in this ratio. The literature shows that gasoline engine combustion has the highest ratio, and natural gas combustion has the lowest value among the 8 sources. In this study, this ratio in indoor samples was lower than on-duty samples because of the contribution of the gasoline engine emission. Males and smokers showed a higher ratio than females and nonsmokers because of the contribution of ETS. Cooking times had a bidirectional effect on this ratio because the combustion of natural gas in kitchens will drive the ratio down, but the $\mathrm{CF}$ source emissions will drive the ratio higher.

For $\mathrm{BaA} /(\mathrm{BaA}+\mathrm{Chr})$, the ratios in this study were higher than the sources reported by others with on-duty $>$ indoor $>$ all-day. Males and smokers were lower than females and nonsmokers. Cooking frequency had a negative effect.

\subsection{Risk assessment due to exposure to PAHs}

Assessment of the health risk PAHs pose to TAs can cite the cancer incidence and then promote occupational 
Table 1 Difference of exposure level $\left(\mathrm{ng} / \mathrm{m}^{3}\right)$ based on the gender, smoke status and cooking frequency $(n=33)$

\begin{tabular}{|c|c|c|c|c|c|c|c|}
\hline \multirow[t]{2}{*}{ PAHs } & \multicolumn{2}{|c|}{ Gender } & \multicolumn{2}{|c|}{ Smoke } & \multicolumn{3}{|c|}{ Cooking frequency } \\
\hline & $\begin{array}{l}\text { Female } \\
(n=10)\end{array}$ & $\begin{array}{l}\text { Male } \\
(n=23)\end{array}$ & $\begin{array}{l}\text { Smoker } \\
(n=20)\end{array}$ & $\begin{array}{l}\text { Nonsmoker } \\
(n=13)\end{array}$ & $\begin{array}{l}1 \text { times per day } \\
(n=4)\end{array}$ & $\begin{array}{l}2 \text { times per day } \\
(n=18)\end{array}$ & $\begin{array}{l}3 \text { times per day } \\
(n=11)\end{array}$ \\
\hline Phe & $82.47(49.8)^{\mathrm{a}}$ & $104.77(30.93)$ & $106.86(32.67)$ & $84.4(45.14)$ & $85.07(37.84)$ & $98.38(22.72)$ & $98.01(84.99)$ \\
\hline Ant & $63.02(53.88)$ & 87.49 (33.49) & 89.67 (35.37) & $65.31(48.89)$ & $66.41(40.57)$ & $80.25(25.1)$ & 80.07 (91.84) \\
\hline Fluo & $22.74(28.05)$ & 32.68 (13.37) & 33.68 (13.97) & $23.5(25.65)$ & $21.27(11.71)$ & $27.2(15.95)$ & 29.67 (49.39) \\
\hline Pyr & $55.73(37.41)$ & 74.05 (25.69) & 76.04 (26.59) & $56.89(36)$ & $57.29(21.8)$ & $66.07(25.02)$ & $68.5(67.57)$ \\
\hline $\mathrm{BaA}$ & $154.51(47.4)$ & 149.07 (19.09) & $151.13(19.72)$ & $150.24(43.08)$ & $142.8(20.67)$ & $147.28(24.34)$ & $150.77(67.94)$ \\
\hline Chr & $62.15(86.75)$ & $72.84(32.33)$ & $77.39(30.17)$ & $57.96(79.05)$ & $61.63(28.9)$ & $60.67(34.67)$ & $69.5(133.1)$ \\
\hline BbFlu & $146.36(42.1)$ & $142.51(31.36)$ & $145.05(32.11)$ & $141.56(38.91)$ & $155.38(21.01)$ & $139.18(31.27)$ & $143.68(71.95)$ \\
\hline BkFlu & $89.93(47.51)$ & $121.38(55.83)$ & $125.52(57.26)$ & $90.81(46.37)$ & $148.01(44.19)$ & $101.85(34.31)$ & $111.85(120.67)$ \\
\hline $\mathrm{BeP}$ & $111.98(51.04)$ & $131.94(50.47)$ & $137.85(52.44)$ & $107.51(51.19)$ & $116.76(57.43)$ & $125.77(46)$ & $125.89(74.56)$ \\
\hline $\mathrm{BaP}$ & $120.66(54.93)$ & $152.02(51.31)$ & $155.99(54.11)$ & $121.8(53.97)$ & $126.3(69.69)$ & $139.28(45.73)$ & $142.52(51.37)$ \\
\hline $\mathrm{InP}$ & $232.81(56.86)$ & $234.22(43.35)$ & $239.31(44.5)$ & $225.69(52.98)$ & $233.51(35.28)$ & 226.37 (49.64) & $233.78(58.83)$ \\
\hline DiBahA & $132.82(7.92)$ & $131.17(4.84)$ & $131.73(4.84)$ & $130.79(7.92)$ & $126.74(2.65)$ & $129.17(6.98)$ & $131.47^{\mathrm{b}}$ \\
\hline BghiP & $129.86(23.44)$ & $129.23(17.92)$ & $130.82(18.33)$ & $127.27(21.75)$ & $132.38(16.18)$ & $127.51(19.58)$ & $129.42(25.17)$ \\
\hline Cor & $219.18(36.03)$ & $222.98(24.11)$ & $225.52(24.28)$ & $215.59(33.66)$ & $219.62(20.22)$ & $217.99(30.98)$ & $222(25.04)$ \\
\hline$\Sigma 14$ PAHs & $1624.23(579.68)$ & 1786.35 (388.63) & $1826.57(402.58)$ & $1599.33(542.87)$ & $1693.15(389.61)$ & $1686.96(366.76)$ & $1737.13(960.96)$ \\
\hline
\end{tabular}

a Mean and standard deviation (in parentheses).

${ }^{\mathrm{b}}$ Only one sample was detected in this PAHs species.

Table 2 Diagnostic ratios based on the gender, smoking status and cooking frequency

\begin{tabular}{|c|c|c|c|c|c|}
\hline Diagnostic ratio & $\mathrm{InP} /(\mathrm{InP}+\mathrm{BghiP})$ & BaP/BghiP & Flu/(Flu+Pyr) & Ant/(Ant+Phe) & $\mathrm{BaA} /(\mathrm{BaA}+\mathrm{Chr})$ \\
\hline On-duty $(n=25)$ & 0.63 & 1.27 & 0.24 & 0.43 & 0.79 \\
\hline All-day $(n=33)$ & 0.64 & 1.10 & 0.30 & 0.45 & 0.68 \\
\hline Indoor $(n=10)$ & 0.64 & 0.99 & 0.30 & 0.37 & 0.71 \\
\hline Female $(n=10)$ & 0.64 & 0.93 & 0.29 & 0.43 & 0.71 \\
\hline Male $(n=23)$ & 0.64 & 1.18 & 0.31 & 0.46 & 0.67 \\
\hline Smoker $(n=20)$ & 0.65 & 1.19 & 0.31 & 0.46 & 0.66 \\
\hline Nonsmoker $(n=13)$ & 0.64 & 0.96 & 0.29 & 0.44 & 0.72 \\
\hline Cooking 1 times per day $(n=4)$ & 0.64 & 0.95 & 0.27 & 0.44 & 0.70 \\
\hline Cooking 2 times per day $(n=18)$ & 0.64 & 1.09 & 0.29 & 0.45 & 0.71 \\
\hline Cooking 3 times per day $(n=11)$ & 0.64 & 1.10 & 0.30 & 0.45 & 0.68 \\
\hline Gasoline engine & $0.18^{\mathrm{a}}$ & $0.5-0.6^{\mathrm{b}}$ & $<0.5^{\mathrm{c}}$ & $0.50^{\mathrm{d}}$ & $0.49^{\mathrm{e}}$ \\
\hline Diesel engine & $0.35-0.7^{\mathrm{f}}$ & $0.3-0.4^{\mathrm{g}}$ & $>0.5^{\mathrm{c}}$ & $0.35^{\mathrm{d}}$ & $0.68^{\mathrm{e}}$ \\
\hline Coal/coke & $0.33^{\mathrm{h}}$ & $>1.25^{\mathrm{b}}$ & $0.53^{\mathrm{i}}$ & - & $0.50^{\mathrm{h}}$ \\
\hline Coal burning & $0.56^{\mathrm{f}}$ & $0.9-6.6^{\mathrm{j}}$ & $0.57^{\mathrm{k}}$ & $0.24^{\mathrm{d}}$ & $0.46^{\mathrm{k}}$ \\
\hline Wood combustion & $0.62^{1}$ & - & $0.51^{\mathrm{k}}$ & $0.16^{\mathrm{k}}$ & $0.43^{\mathrm{m}}$ \\
\hline Natural gas combustion & $0.32^{\mathrm{k}}$ & - & $0.49^{\mathrm{k}}$ & $0.12^{\mathrm{k}}$ & $0.39^{\mathrm{k}}$ \\
\hline $\mathrm{CF}$ (cooking fume $)^{\mathrm{n}}$ & 0.40 & 1.33 & 0.69 & 0.48 & 0.43 \\
\hline ETS (environmental tobacco smoke) ${ }^{\mathrm{n}}$ & 0.52 & 1.89 & 0.77 & 0.39 & 0.30 \\
\hline
\end{tabular}

${ }^{\mathrm{a}}$ Wang et al., 2008; Del.Rosario Sienra et al., 2005; ${ }^{\mathrm{b}}$ Ravindra et al., 2008; ${ }^{\mathrm{c}}$ Ravindra et al., 2008; Ravindra et al., 2006; ${ }^{\mathrm{d}}$ Guo et al., 2003; ${ }^{\mathrm{K}}$ Khalili et al., 1995; Vasilakos et al., 2007; f Wang et al., 2008; Del.Rosario Sienra et al., 2005; Ravindra et al., 2008; Ravindra et al., 2006; Vasilakos et al., 2007; Saarnio et al., 2008; ${ }^{\mathrm{g} B}$ Bourotte et al., 2005; ${ }^{\mathrm{h}}$ Tang et al., 2005; Saarnio et al., 2008; ${ }^{\mathrm{j}}$ Akyüz and Çabuk, 2008; ${ }^{\mathrm{k}}$ Galarneau, 2008; ${ }^{\mathrm{l}}$ Del Rosario Sienra et al., 2005; Ravindra et al., 2008; Akyüz and Çabuk, 2008; Mantis et al., 2005; ${ }^{\mathrm{m}}$ Akyüz and Çabuk, 2008; Mantis et al., 2005 ; ${ }^{\mathrm{Z}} \mathrm{Zhang}$ et al., 2009.

-: no reported.

protection. A Monte Carlo simulation was performed to assess the risk of exposure of TAs to PAHs based on the ILCR. After running the simulation 1000, 5000 and 10,000 times, the risk and sensitivity were described in Table 3 .

All of the constants were listed and evaluated according to the reference. IR (breath volume) obeys a triangular distribution according to the report of USEPA (1997). The minimum, most probable and maximum values are 1.1, 1.3 and $1.5 \mathrm{~m}^{3} / \mathrm{hr}$. Chen and Liao (2006) have summarized the potency of the BaP cancer slope factors (Collins et al., 1991; OEHHA, 1993; Thyssen et al., 1981), and they concluded that the CSF of BaP obeys a lognormal 


\begin{tabular}{|c|c|c|c|c|}
\hline Parameter & Input & $\begin{array}{l}\text { Trial } \\
\text { number }\end{array}$ & $\begin{array}{l}\text { Risk } \\
\left(\times 10^{-4}\right)\end{array}$ & Sensitivity of risk \\
\hline Breath volume & Triangular $(1.3,1.1-1.4)$ & 1000 & $1.062 \pm 0.80$ & CSF: $66.0 \%$; TEC $_{\mathrm{BaP}}: 32.2 \%$; breath volume: $1.2 \%$; body weight: $-0.6 \%$ \\
\hline Body weight & Lognormal $(65,5)$ & 3000 & $1.034 \pm 0.76$ & CSF: $63.1 \%$; TEC $_{\mathrm{BaP}}: 35.7 \%$; breath volume: $1.1 \%$; body weight: $0 \%$ \\
\hline $\mathrm{TEC}_{\mathrm{BaP}}$ & Lognormal $(263.22,110.79)$ & 5000 & $1.047 \pm 0.75$ & CSF: $63.0 \%$; TEC $_{\mathrm{BaP}}: 36.1 \%$; breath volume: $0.7 \%$; body weight: $-0.2 \%$ \\
\hline CSF & Lognormal $(3.14,1.80)$ & 8000 & $1.055 \pm 0.79$ & CSF: $64.4 \%$; TEC $_{\mathrm{BaP}}: 34.6 \%$; breath volume: $1.0 \%$; body weight: $0 \%$ \\
\hline $\mathrm{EF}$ & 250 & 10000 & $1.053 \pm 0.79$ & CSF: $63.8 \%$; TEC $_{\mathrm{BaP}}: 35.3 \%$; breath volume: $0.8 \%$; body weight: $-0.1 \%$ \\
\hline ED & 25 & & & \\
\hline AT & 70 & & & \\
\hline
\end{tabular}

* Output was calculated by $\frac{(\mathrm{CSF} \times \mathrm{TEC} / 1000000 \times \text { breath volume } \times \mathrm{EF} \times \mathrm{ED})}{(\text { body }}$

distribution $(3.14,1.80)$. After an exploratory study, we found that the $\mathrm{TEC}_{\mathrm{BaP}}$ obeys a lognormal distribution (263.22, 110.79). All of the parameters (Table 3) were applied in the Monte Carlo simulation.

After 1000, 3000, 5000, 8000 and 10000 iterations, the results showed that 8000 trials are sufficient to ensure the stability of the results. The cancer risk to the TAs was $1.055 \times 10^{-4}(95 \% \mathrm{CI}$ (confidence interval): $2.81 \times$ $10^{-5}$ to $2.52 \times 10^{-4}$ ) which is higher than in the primary studies by $\mathrm{Hu}$ et al. (2007). Hu et al. (2007) reported that the risk posed by PAHs for policeman in Tianjin was approximately $2.1 \times 10^{-5}$ to $6.7 \times 10^{-5}$. For both the traffic policeman and the traffic assistants, the PAH inhalation exposure risk was remarkably larger than the negligible risk level (approximately $10^{-6}$ ). This risk scale was 2-3 times the risk of sintering workers in Taiwan (Lin et al., 2008), less than the workers in a carbon black factory (Tsai et al., 2001), and approximately $10 \%$ that of workers in 2 foundries (Liu et al., 2010) in Taiwan. The risk was 2-3 fold higher than the risk of Beijing traffic police officers (approximately $4.16 \times 10^{-4}-5.83 \times 10^{-4}$ ) (Liu et al., 2007b).

The results of the sensitivity analysis showed that the CSF is the most important contributor $(64.4 \%)$ to the uncertainty of this forecast, and the next contributors are the $\mathrm{TEC}_{\mathrm{BaP}}(34.6 \%)$, breath volume $(1.0 \%)$ and body weight $(0 \%)$. Most of the uncertainty of the risk assessment is due to these factors. In the future, a more detailed toxicology database can show less uncertainty in the evaluation. Use of a PAH concentration monitor is another way to strength the simulation.

\subsection{Exposure source apportionment}

Few studies focus on exposure source identification (Anderson et al., 2001; Brinkman et al., 2009; Miller et al., 2002; Yakovleva et al., 1999), and PMF and PCA are the main methods applied. The earlier studies focused on the personal exposure to VOCs and particulate matter.

In this study, 13 PAHs (except for the DiBahA, which had a low detected ratio in 33 samples) were rearranged by principal component analysis using PASW Statistics 18.
After a one-tailed $t$-Test, most of the individual PAHs show a significant correlation. The Kaiser-Meyer-Olkin statistics value is 0.75 (more than 0.7). The Bartlett's Test of Sphericity statistics value is 657 and the significance is $0.00(p<0.05)$. All of the above information indicates that this database is fit for factor analysis. Based on the "Principal Component Analysis" method, 4 factors were extracted. A total 33 samples were rearranged according to the 4 factors shown in Table 4 . The total explained variances of Factors 1 to 4 were $25.14 \%, 24.06 \%, 20.16 \%$ and $18.85 \%$, respectively.

In Factor 1, 5-ring compounds (BkFlu, BeP and BaP) are the predominant compounds. This factor is associated

\begin{tabular}{|c|c|c|c|c|}
\hline $\begin{array}{l}\text { Compound } \\
\text { (rings) }\end{array}$ & Factor 1 & Factor 2 & Factor 3 & Factor 4 \\
\hline Phe (3) & 0.22 & 0.15 & 0.01 & 0.94 \\
\hline Ant (3) & 0.22 & 0.15 & 0.02 & 0.94 \\
\hline Fluo (4) & 0.37 & 0.43 & 0.36 & 0.62 \\
\hline Pyr (4) & 0.43 & 0.41 & 0.45 & 0.61 \\
\hline $\mathrm{BaA}(4)$ & 0.12 & 0.77 & 0.13 & 0.28 \\
\hline Chr (4) & 0.23 & 0.81 & 0.16 & 0.40 \\
\hline BbFlu (5) & 0.56 & 0.63 & 0.23 & 0.20 \\
\hline BkFlu (5) & 0.81 & 0.38 & 0.00 & 0.17 \\
\hline $\mathrm{BeP}(5)$ & 0.73 & 0.29 & 0.43 & 0.33 \\
\hline $\mathrm{BaP}(5)$ & 0.82 & - & 0.30 & 0.36 \\
\hline $\operatorname{InP}(6)$ & 0.13 & 0.69 & 0.64 & - \\
\hline BghiP (6) & 0.22 & 0.61 & 0.69 & - \\
\hline Cor (7) & 0.21 & 0.11 & 0.89 & 0.19 \\
\hline Variance $(\%)$ & 25.14 & 24.06 & 20.16 & 18.85 \\
\hline $\begin{array}{l}\text { Cumulative } \\
\text { variance }(\%)\end{array}$ & 25.14 & 49.21 & 69.37 & 88.22 \\
\hline Eigenvalues & 2.77 & 3.14 & 2.36 & 3.12 \\
\hline Potential sources & $\mathrm{DE}$ & GE and ETS & $\mathrm{CC}$ & $\mathrm{CF}$ and $\mathrm{PV}$ \\
\hline
\end{tabular}

DE: diesel exhaust, GE: gasoline exhaust, ETS: environmental tobacco smoke, CC: coal combustion, CF: cooking fumes, PV: petroleum volatized from gasoline stations, -: no detected or no calculated.

The bold values are the components that have a factorial weight more than 0.6. Negative values are not been shown in this table. 
with diesel exhaust emissions (Guo et al., 2003; Khalili et al., 1995). In factor 2 , the high factor loading compounds were $\mathrm{BaA}$ (0.77) and $\mathrm{Chr}$ (0.81). All of the dominant compounds were 4-ring PAHs. From the literature, this factor is associated with gasoline exhaust emissions (Shah et al., 2005) and environmental tobacco smoke (Zhang et al., 2009). The heaviest weighted species (6-7-ring compounds, BgihP and Cor) represented Factor 3. The higher molecular weight PAHs originated mainly from pyrolytic processes such as coal combustion. In Factor 4, the dominant compounds were Phe (0.94) and Ant (0.94) which are low molecular weight compounds and come from unburned diesel oil and gasoline (Dachs et al., 2002). Khalili et al. (1995) have reported that the PAHs with small numbers of rings could be tested in diesel and gasoline samples. Some publications reported that PAHs from cooking fumes have low molecular weight species as the main constituents (Zhang et al., 2009).

The exposure of the TAs to PAHs by inhalation may come from many sources, not simply occupational exposure (automobile exhaust), public exposure (industrial emissions, such as coal combustion) and indoor emission sources (such as cooking activities and tobacco smoke). For the sake of controlling exposure and decreasing the risk, indoor emissions are as important as outdoor emissions.

\subsection{Limitations}

First, the results of the study have shown that there is a great variability in TAs' particulate-bound PAHs exposure. In addition, the limited sample size makes this study only a preliminary study of TAs' particulate-bound PAH exposure, and more robust results should be obtained on the basis of a wider range investigation.

Secondly, some deviation can come from the limited summer samples in the calculation of the lifetime cancer risk and individual exposure source apportionment. Based on the Winter/Summer value of particulate-bound PAH concentration varying from 2 to 10 ( $\mathrm{Hu}$ et al., 2007a), the lifetime cancer risk may be underestimated. Also, the contribution of different sources was restricted in summer.

Thirdly, the gaseous parts of PAHs (gPAHs) were not included in this study. Although the TEFs of gPAHs (such as Nap) were smaller than those of large MW PAHs (5-6 rings), the actual impact to total lifetime cancer risk cannot be assessed.

Lastly, the diagnostic ratio method and PCA method are qualitative identification pPAH sources. More refined exposure source apportionment should be based on quantitative evaluation methods (such as, PMF and CMB).

\section{Conclusions}

In the present study, we find that the total exposure to 14
PAHs in $\mathrm{PM}_{10}$ is approximately $2871 \pm 928 \mathrm{ng} / \mathrm{m}^{3}$ (onduty), $1622 \pm 457 \mathrm{ng} / \mathrm{m}^{3}$ (all-day) and the indoor $\mathrm{PAH}$ level is $1257 \pm 107 \mathrm{ng} / \mathrm{m}^{3}$. The scarcest and most abundant species of 14 PAHs in on-duty, all-day and indoor samples are Fluo and Cor, Fluo and InP, Fluo and InP, respectively. The BaP concentration of TAs inhaled in Tianjin were $310.61 \mathrm{ng} / \mathrm{m}^{3}$ (on-duty), $142.52 \mathrm{ng} / \mathrm{m}^{3}$ (allday) and $117.83 \mathrm{ng} / \mathrm{m}^{3}$ (indoor), values that are higher than both the SEPA and WHO standards for air quality. The PAH exposure concentration is higher for smokers than nonsmokers, and the concentration is higher for males than females. The exposure levels for TAs are higher than SEPA air quality standards. Summarizing the ratio analysis, we can find that the exposure can come from various source emissions. After a Monte Carlo simulation, results show that the PAH exposure can create a cancer risk of approximately $1.055 \times 10^{-4}\left(95 \% \mathrm{CI}: 2.81 \times 10^{-5}\right.$ to $2.52 \times 10^{-4}$ ), higher than the result of $\mathrm{Hu}$ et al. (2007) in Tianjin and approximately 2-3-fold that of the result of Liu et al. (2007c) in Beijing. The CSF (64\%) and $\mathrm{TEC}_{\mathrm{BaP}}$ $(35 \%)$ contribute the major uncertainty to this risk. After source rearrangement by PCA, 4 factors are derived from the 33 exposure samples. Factor 1 stands for the diesel exhaust, Factor 2 for gasoline exhaust, Factor 3 for coal combustion and Factor 4 for cooking fumes and petroleum volatilized from gasoline stations. Except for the mobile exhaust, coal combustion and cooking play important roles in total PAH exposure, suggesting a need for a total control of multi-source PAH exposure to control the exposure and protect the health of TAs.

\section{Acknowledgments}

This work was supported by the Chinese National Science Funding Council (No. 20807002, 20307006), and the National Basic Research Program of China (No. 2011CB503801). The authors are very thankful to Mrs. Meng Fenglin and Mrs. Liu Haifeng for their help in GC/MS.

R E F E R E N C E S

Akyüz, M., Çabuk, H., 2008. Particle-associated polycyclic aromatic hydrocarbons in the atmospheric environment of Zonguldak, Turkey. Sci. Total Environ. 405, 62-70.

Anderson, M.J., Miller, S.L., Milford, J.B., 2001. Source apportionment of exposure to toxic volatile organic compounds using positive matrix factorization. J. Expo. Anal. Environ. Epidemiol. 11, 295307.

Arfsten, D.P., Schaeffer, D.J., Mulveny, D.C., 1996. The effects of near ultraviolet radiation on the toxic effects of polycyclic aromatic hydrocarbons in animals and plants: a review. Ecotoxicol. Environ. Saf. 33, 1-24.

Bourotte, C., Forti, M., Taniguchi, S., Bicego, M., Lotufo, P., 2005. A wintertime study of PAHs in fine and coarse aerosols in São Paulo city, Brazil. Atmos. Environ. 39, 3799-3811. 
Brinkman, G.L., Milford, J.B., Schauer, J.J., Shafer, M.M., Hannigan, M.P., 2009. Source identification of personal exposure to fine particulate matter using organic tracers. Atmos. Environ. 43, 1972 1981.

Chen, S.C., Liao, C.M., 2006. Health risk assessment on human exposed to environmental polycyclic aromatic hydrocarbons pollution sources. Sci. Total Environ. 366, 112-123.

Collins, J.F., Brown, J.P., Dawson, S.V., Marty, M.A., 1991. Risk assessment for benzo[a]pyrene. Regul. Toxicol. Pharmacol. 13, 170-184.

Del, Rosario, Sienra, M., Rosazza, N., Prendez, M., 2005. Polycyclic aromatic hydrocarbons and their molecular diagnostic ratios in urban atmospheric respirable particulate matter. Atmosph. Res. 75, 267-281.

Fent, K., Bätscher, R., 2000. Cytochrome P4501A induction potencies of polycyclic aromatic hydrocarbons in a fish hepatoma cell line: Demonstration of additive interactions. Environ. Toxicol. Chem. 19, 2047-2058.

Gabos, S., Ikonomou, M.G., Schopflocher, D., Fowler, B.R., White, J., Prepas, E. et al., 2001. Characteristics of PAHs, PCDD/Fs and PCBs in sediment following forest fires in northern Alberta. Chemosphere 43, 709-719.

Galarneau, E., 2008. Source specificity and atmospheric processing of airborne PAHs: Implications for source apportionment. Atmos. Environ. 42, 8139-8149.

Guo, H., Lee, S.C., Ho, K.F., Wang, X.M., Zou, S.C., 2003. Particleassociated polycyclic aromatic hydrocarbons in urban air of Hong Kong. Atmos. Environ. 37, 5307-5317.

Hu, Y., Bai, Z., Zhang, L., Wang, X., Yu, Q., Zhu, T., 2007. Health risk assessment for traffic policemen exposed to polycyclic aromatic hydrocarbons (PAHs) in Tianjin, China. Sci. Total Environ. 382, 240-250.

Khalili, N.R., Scheff, P.A., Holsen, T.M., 1995. PAH source fingerprints for coke ovens, diesel and, gasoline engines, highway tunnels, and wood combustion emissions. Atmos. Environ. 29, 533-542.

Larsen, R.K., Baker, J.E., 2003. Source apportionment of polycyclic aromatic hydrocarbons in the urban atmosphere: A comparison of three methods. Environ. Sci. Technol. 37, 1873-1881.

Lin, Y.C., Lee, W.J., Chen, S.J., Chang, G.P., Tsai, P.J., 2008. Characterization of PAHs exposure in workplace atmospheres of a sinter plant and health-risk assessment for sintering workers. J. Hazard. Mater. $158,636-643$.

Liu, H.H., Yang, H.H., Chou, C.D., Lin, M.H., Chen, H.L., 2010. Risk assessment of gaseous/particulate phase PAH exposure in foundry industry. J. Hazard. Mater. 181, 105-111.

Liu, Y., Tao, S., Dou, H., Zhang, T., Zhang, X., Dawson, R., $2007 \mathrm{a}$. Exposure of traffic police to polycyclic aromatic hydrocarbons in Beijing, China. Chemosphere 66, 1922-1928.

Liu, Y., Tao, S., Yang, Y., Dou, H., Coveney, R., 2007b. Inhalation exposure of traffic police officers to polycyclic aromatic hydrocarbons (PAHs) during the winter in Beijing, China. Sci. Total Environ. 383, 98-105.

Liu, Y. N., Tao, S., Dou, H., Zhang, T.W., Zhang, X.L., Dawson, R., 2007c. Exposure of traffic police to polycyclic aromatic hydrocarbons in Beijing, China. Chemosphere 66, 1922-1928.

Manoli, E., Kouras, A., Samara, C., 2004. Profile analysis of ambient and source emitted particle-bound polycyclic aromatic hydrocarbons from three sites in northern Greece. Chemosphere 56, 867-878.
Mantis, J., Chaloulakou, A., Samara, C., 2005. PM 10 -bound polycyclic aromatic hydrocarbons (PAHs) in the greater area of Athens, Greece. Chemosphere 59, 593-604.

Miller, S.L., Anderson, M.J., Daly, E.P., Milford, J.B., 2002. Source apportionment of exposures to volatile organic compounds. I. Evaluation of receptor models using simulated exposure data. Atmos. Environ. 36, 3629-3641.

Mumford, J.L., Li, X.M., Hu, F.D., Lu, X.B., Chuang, J.C., 1995. Human exposure and dosimetry of polycyclic aromatic hydrocarbons in urine from Xuan Wei, China with high lung cancer mortality associated with exposure to unvented coal smoke. Carcinogenesis 16, 3031-3036.

Nisbet, I.C., LaGoy, P.K., 1992. Toxic equivalency factors (TEFs) for polycyclic aromatic hydrocarbons (PAHs). Regul. Toxicol. Pharmacol. 16, 290-300.

Oanh, N.T.K., Reutergardh, L.B., Dung, N.T., 1999. Emission of polycyclic aromatic hydrocarbons and particulate matter from domestic combustion of selected fuels. Environ. Sci. Technol. 33, 27032709.

OEHHA (Office of Environmental Health Hazard Assessment), 1993. Benzo[a]pyrene as a toxic air contaminant, part B, health effects of Benzo[a]pyrene (Air Toxicology and Epidemiology Section). Berkeley, CA.

Ravindra, K., Bencs, L., Wauters, E., Dehoog, J., Deutsch, F., Roekens, E. et al., 2006. Seasonal and site-specific variation in vapour and aerosol phase PAHs over Flanders (Belgium) and their relation with anthropogenic activities. Atmos. Environ. 40, 771-785.

Ravindra, K., Sokhi, R., Vangrieken, R., 2008. Atmospheric polycyclic aromatic hydrocarbons: Source attribution, emission factors and regulation. Atmos. Environ. 42, 2895-2921.

Ruchirawa, M., Mahidol, C., Tangjarukij, C., Pui-ock, S., Jensen, O., Kampeerawipakorn, O. et al., 2002. Exposure to genotoxins present in ambient air in Bangkok, Thailand-particle associated polycyclic aromatic hydrocarbons and biomarkers. Sci. Total Environ. 287, 121-132.

Saarnio, K., Sillanpaa, M., Hillamo, R., Sandell, E., Pennanen, A., Salonen, R., 2008. Polycyclic aromatic hydrocarbons in sizesegregated particulate matter from six urban sites in Europe. Atmosph. Environ. 42, 9087-9097.

Shah, S.D., Ogunyoku, T.A., Miller, J.W., Cocker, D.R., 2005. On-road emission rates of PAH and $n$-alkane compounds from heavy-duty diesel vehicles. Environ. Sci. Technol. 39, 5276-5284.

Szaniszló, J., Ungváry, G., 2001. Polycyclic aromatic hydrocarbon exposure and burden of outdoor workers in budapest. J. Toxicol. Environ. Health: Part A 62, 297-306.

Tang, N., Hattori, T., Taga, R., Igarashi, K., Yang, X., Tamura, K. et al., 2005. Polycyclic aromatic hydrocarbons and nitropolycyclic aromatic hydrocarbons in urban air particulates and their relationship to emission sources in the Pan-Japan Sea countries. Atmos. Environ. 39, 5817-5826.

Thyssen, J., Althoff, J., Kimmerle, G., Mohr, U., 1981. Inhalation studies with benzo[a]pyrene in Syrian golden hamsters. J. Nat. Cancer Inst. $66,575-577$.

Tsai, P.J., Shieh, H.Y., Lee, W.J., Lai, S.O., 2001. Health-risk assessment for workers exposed to polycyclic aromatic hydrocarbons (PAHs) in a carbon black manufacturing industry. Sci. Total Environ. 278, 137-150.

US EPA (Environmental Protection Agency), 1991. Risk assessment 
guidance for superfund, volume I: human health evaluation manual, supplemental guidance: "Standard default exposure factors" interim final, Washington D.C.

US EPA (Environmental Protection Agency), 1997. Exposure factors handbook, update to exposure factors handbool, EPA/600/889/043-May 1989.

Vanrooij, J.G.M., Veeger, M.M.S., Bodelierbade, M.M., Scheepers, P.T.J., Jongeneelen, F.J., 1994. Smoking and dietary-intake of polycyclic aromatic-hydrocarbons as sources of interindividual variability in the base-line excretion of 1-hydroxypyrene in urine. Int. Arch. Occup. Environ. Health 66, 55-65.

Vasilakos, C., Levi, N., Maggos, T., Hatzianestis, J., Michopoulos, J., Helmis, C., 2007. Gas-particle concentration and characterization of sources of PAHs in the atmosphere of a suburban area in Athens, Greece. J. Hazard. Mater. 140, 45-51.

Wang, X., Cheng, H., Xu, X., Zhuang, G., Zhao, C., 2008. A wintertime study of polycyclic aromatic hydrocarbons in $\mathrm{PM}_{2.5}$ and $\mathrm{PM}_{2.5-10}$ in Beijing: Assessment of energy structure conversion. J. Hazard. Mater. 157, 47-56.
WHO (World Health Organization), 2000. Air Quality Guidelines for Europe. WHO Regional Publications, European Series.

Wild, S.R., Jones, K.C., 1995. Polynuclear aromatic-hydrocarbons in the united-kingdom environment - a preliminary source inventory and budget. Environ. Pollut. 88, 91-108.

Yakovleva, E., Hopke, P.K., Wallace, L., 1999. Receptor modeling assessment of particle total exposure assessment methodology data. Environ. Sci. Technol. 33, 3645-3652.

Zhang, L., Bai, Z., You, Y., Wu, J., Feng, Y., Zhu, T., 2009. Chemical and stable carbon isotopic characterization for PAHs in aerosol emitted from two indoor sources. Chemosphere 75, 453-461.

Zhang, W., Xu, D., Zhuang, G., Ding, C., Wang, G., Chang, J. et al., 2006. A pilot study on using urinary 1-hydroxypyrene biomarker for exposure to PAHs in Beijing. Environ. Monit. Assess. 131, $387-$ 394.

Zolotov, M.Y., Shock, E.L., 2000. A thermodynamic assessment of the potential synthesis of condensed hydrocarbons during cooling and dilution of volcanic gases. J. Geophys. Res. -Solid Earth 105, 539559. 